\title{
Determinantes da prática do gerenciamento financeiro por produtores rurais na microrregião de Salgueiro, Brasil
}

\author{
Determinants of the practice of financial management by rural producers in the microregion of \\ Salgueiro, Brazil \\ Determinantes de la práctica de gestión financiera de productores rurales en la microregión de \\ Salgueiro, Brasil
}

Recebido: 21/07/2021 | Revisado: 26/07/2021 | Aceito: 28/07/2021 | Publicado: 04/08/2021

\author{
Micael dos Santos Gomes \\ ORCID: https://orcid.org/0000-0001-5728-0240 \\ Universidade de Pernambuco, Brasil \\ E-mail: micael.santos@upe.br \\ Eryka Fernanda Miranda Sobral \\ ORCID: https://orcid.org/0000-0003-0288-9037 \\ Universidade de Pernambuco, Brasil \\ E-mail: eryka.sobral@upe.br \\ Raimundo Nonato Lima Filho \\ ORCID: https://orcid.org/0000-0003-4953-5260 \\ Universidade de Pernambuco, Brasil \\ E-mail: raimundo.lima@upe.br \\ Fagner José Coutinho de Melo \\ ORCID: https://orcid.org/0000-0002-0550-5177 \\ Universidade de Pernambuco, Brasil \\ E-mail: fagner.melo@upe.br \\ Wellington Charles Lacerda Nobrega \\ ORCID: https://orcid.org/0000-0003-0634-9396 \\ E-mail: wellington_charles@hotmail.com \\ Universidade Federal da Paraíba, Brasil \\ Silvio André Vital Junior \\ ORCID: https://orcid.org/0000-0003-2797-1563 \\ E-mail: silvio@garoahabitat.com \\ Universidade Federal de Pernambuco, Brasil
}

\begin{abstract}
Resumo
O objetivo deste estudo é analisar os determinantes da gestão financeira dos agricultores rurais da microrregião de Salgueiro, Brasil. Foram utilizados dados primários coletados por método survey a partir de aplicação de questionário com produtores rurais da microrregião do município de Salgueiro. A partir de análise logística pôde-se evidenciar que a maior escolaridade e comportamentos relacionados às práticas de planejamento operacional e estratégico dos produtores rurais da referida região tem influenciado positivamente na maior tendência às práticas de gestão financeira. Por outro lado, empreendimentos rurais estruturados do tipo de agricultura familiar tem menor tendência as referidas práticas demonstrando a necessidade de ações de políticas públicas que fomentem maior qualificação para com essa população na região.
\end{abstract}

Palavras-chave: Gestão Financeira; Produtor Rural; Planejamento de Gestão.

\begin{abstract}
The aim of this study is to analyze the determinants of financial management of rural farmers in the microregion of Salgueiro, Brazil. Primary data collected through a survey method were used, using a questionnaire with rural producers in the micro-region of the municipality of Salgueiro. From the logistical analysis, it was possible to evidence that the higher education and behaviors related to the operational and strategic planning practices of the rural producers in that region has positively influenced the greater tendency towards financial management practices. On the other hand, structured rural enterprises of the family farming type have a lower tendency towards these practices, demonstrating the need for public policy actions that foster greater qualification for this population in the region.
\end{abstract}

Keywords: Financial Management; Rural Producer; Management Planning.

\section{Resumen}


El objetivo de este estudio es analizar los determinantes de la gestión financiera de los agricultores rurales en la microrregión de Salgueiro, Brasil. Se utilizaron datos primarios recolectados mediante un método de encuesta, utilizando un cuestionario con productores rurales de la microrregión del municipio de Salgueiro. Del análisis logístico se pudo evidenciar que la educación superior y los comportamientos relacionados con las prácticas de planificación operativa y estratégica de los productores rurales de esa región han influido positivamente en la mayor tendencia hacia prácticas de gestión financiera. Por otro lado, las empresas rurales estructuradas del tipo agricultura familiar tienen una menor tendencia hacia estas prácticas, lo que demuestra la necesidad de acciones de política pública que propicien una mayor calificación de esta población en la región.

Palabras clave: Gestión financeira; Productor rural; Planificación de la gestión.

\section{Introdução}

No Brasil, de acordo com o Serviço Brasileiro de Apoio às Micro e Pequenas Empresas (SEBRAE, 2010), a falha de gerenciamento financeiro está entre os principais fatores da taxa de mortalidade das empresas. No que se refere às atividades rurais, essa tendência é mais fortemente observada.

A Teoria de Gestão Financeira enfatiza a necessidade de construir fluxo de caixa nas empresas, que nada mais é do que a entrada e saída de dinheiro, que demonstrará realmente a situação e capacidade financeira para satisfazer suas obrigações e adquirir novos ativos a fim de atingir as metas da empresa (Bertoletti, 2015). Todavia, há alguns estudos como os de Rosa e Garcia (2015) e Silva e Andrade (2016) demonstrando que a maioria dos produtores rurais não analisam o desempenho econômico de sua propriedade rural, não obtendo, assim, informações disponíveis quanto aos custos de produção. Em consequência disso, na maior parte das vezes por questão cultural, por exemplo, ignoram a análise de entradas e saídas nas atividades desenvolvidas delimitando claramente possíveis problemas e resultados econômicos de sua propriedade, comprometendo a saúde do seu negócio e possivelmente elevando o êxodo rural (Silva, Rech \& Rech, 2010).

$\mathrm{O}$ ato de gerir e organizar bens e riquezas tornou a gestão financeira indispensável nos dias atuais, dotada de vários ramos ela representa muito mais que números e lançamentos de créditos e débitos, pois através das suas técnicas consolidou-se como uma da principais ferramentas responsáveis para gestão das organizações, seja ela indústria, comércio ou no âmbito rural, sendo que no campo a gestão financeira teve sua evolução tardia, além de uma grande resistência por parte dos empreendedores rurais (Ulrich, 2009).

De acordo com a Agência Estadual de Planejamento e Pesquisas de Pernambuco (Condepe-Fidem, 2019) a atividade agropecuária é considerada a terceira principal atividade econômica do estado. Todavia, dada a hipótese que há uma forte tendência de produtores do setor rural, em média no Brasil, negligenciar atividades de gestão financeira, surge então o questionamento a ser respondido por essa proposta de pesquisa, a saber: o que determina os produtores rurais utilizarem a gestão financeira em seus estabelecimentos para tomada de decisão? Estudar aspectos relacionados à prática da gestão financeira permite reflexão sobre métricas utilizadas para, dentre outras motivações, avaliar desempenho financeiro, justificar necessidades de empréstimos e/ou financiamento, assim como, honrar com esses compromissos tão importantes para aumentar a produção, ampliar lucro e garantir desenvolvimento econômico regional.

Com intuito de responder ao referido problema, essa pesquisa tem por objetivo investigar os determinantes da prática da gestão financeira auxiliando na tomada de decisão dos pequenos produtores rurais da microrregião de Salgueiro, Brasil. Nessa perspectiva, a partir de um modelo logístico pretende-se verificar a influência de características socioeconômicas, características do empreendimento rural, de atitudes de planejamento e uso de tecnologia sobre a frequência de rotinas de gestão financeira dos produtores rurais da microrregião de Salgueiro.

Dentre as contribuições desse estudo destaca-se a melhor compreensão da gestão financeira dos agricultores e as suas percepções acerca do assunto, pois para um melhor andamento de uma organização é evidente a necessidade de demonstrações e implantação de métodos e ferramentas que auxiliem na tomada de decisão, além de ter como aspecto relevante a possibilidade de que a partir dos resultados seja possível desenvolver junto aos agricultores da microrregião de Salgueiro, cuja 
agricultura familiar é atividade predominante, políticas públicas e/ou projetos de extensão de qualificação com o intuito de orientar e consequentemente melhorar os resultados acerca da gestão financeira rural contribuindo, dessa forma, no fomento de desenvolvimento econômico regional.

Dessa forma, este artigo além dessa introdução e das considerações finais, é composto por um referencial teórico e hipóteses formuladas sobre aspectos da gestão financeira nos empreendimentos rurais, na segunda seção. Na terceira seção, pela exposição dos procedimentos metodológicos. Na quarta seção, pela análise e discussão dos resultados da pesquisa.

\section{Fundamentação Teórica e Hipóteses do Estudo}

A crescente disponibilidade de crédito agrícola para as mais diversas classes de produtores rurais, de acordo com Santos, Marion e Segatti (2009), permitiu uma maior competitividade e envolvimento dos produtores rurais com questões trabalhistas, ambientais, e de política tributária nos últimos anos. Essa conjuntura, conforme os autores, evidenciou para os produtores rurais a necessidade de atenção não apenas na sua produção, mas para a gestão do seu negócio, sobretudo, para adoção de políticas eficientes de gestão financeira.

Há tempos, conforme Callado (1999), a gestão dos empreendimentos rurais tem geralmente foco nos fatores do trabalho agrícola, zootécnico e agroindustrial, concentrando modos de produção e conceitos operacionais e técnicos das atividades específicas desenvolvidas. $\mathrm{O}$ autor destaca que a gestão financeira rural é um método administrativo pouco ou não utilizado por nossos agricultores, pois esta técnica gerencial é vista como complexa e de difícil execução e que apresenta um baixo retorno prático, e que a aplicação desse método em empreendimentos rurais é quase sempre por finalidades fiscais, não apresentando uma aplicação gerencial dentro da organização.

No entanto, Borilli (2005) descreve que a finalidade da gestão financeira rural é de conduzir e orientar as operações agrícolas e pecuárias; analisar e controlar o desempenho econômico-financeiro da organização e de cada operação produtiva; amparar as tomadas de decisões no planejamento da produção, das vendas e investimentos; além de fornecer dados e informações que permitem fazer comparações com o rendimentos de outras empresas, auxiliar os produtores nas projeções dos fluxos de caixa e gerar informações fiscais que podem auxiliar na tomada de decisão dos produtores.

Para Silva (2016) a gestão financeira pode ser realizada até mesmo de forma simples por parte dos produtores agrícolas, os quais podem praticá-la anotando todas as entradas e saídas de dinheiro, gastos e investimentos, lucros e prejuízos, possibilitando a elaboração de relatórios mensais ou anuais das atividades agrícolas, como meio de mensurar o andamento financeiro do empreendimento e prospectar ações de crescimento. Por sua vez, De Souza (2016) destaca que a falta da gestão financeira dificulta a percepção de perdas por parte dos produtores rurais, prejudicando o desenvolvimento da atividade como um todo na região.

Mesmo diante de tantas discussões, ainda em anos recentes, é possível encontrar uma série de pesquisas (Della Colleta, 2013; Lisboa, 2015; De Souza, 2016) apontando que diversas características do empreendedor rural podem induzir os empresários a focar a gestão financeira nas mais diversas formas possíveis, já que as características do ambiente local determinam a gestão que melhor se ajusta ao negócio, fazendo os empreendedores rurais nas mais diversas localidades e setores adotarem diferentes praticas de gestão.

Para Della Colleta (2013), ao investigar os instrumentos e a análise da gestão para agricultores de grãos do município de São Gabriel do Oeste-Mato grosso do Sul, ainda há agricultores que não utilizam ou aplicam os recursos de gestão financeira dentro das propriedades, ainda evidencia que a pesquisa busca uma correlação de diversas variáveis dependentes, uma delas é a relação da faixa etária com a área produzida, de acordo com os dados é possível perceber que a faixa etária dos 30 a 39 é quem apresenta as maiores áreas produzidas tendo como justificativa que os mais velhos estão passando o controle para os mais novos, relacionando a faixa etária com a percepção dos lucros/perdas o autor observa que os jovens têm uma 
percepção melhor em relação económica, por possuir mais acesso a informações.

Em média o produtor rural brasileiro, como aponta (Kruger, 2009; Santos, 2009; Lisboa, 2015) tem como principais características socioeconômicas uma predominância do sexo masculino no setor agrícola, ainda destacando que apresentam um baixo nível de escolaridade, concluindo no máximo o ensino fundamental, a faixa etária do agricultor tem uma média de idade entre 30 a 60 anos, destacando a utilização da mão de obra familiar dentro da propriedade, no quesito da área da propriedade e de produção o agricultor apresenta uma variação pequeno, médio e grande produtor, a renda mensal também é reflexo do porte do agricultor.

Com base na pesquisa de Carvalho e Schiozer (2012), o porte do empreendimento tem uma forte relação com a adoção de rotinas de gestão financeira, relaciona que empresas maiores apresentam estruturas de gestão, planejamento e controle com níveis superiores em relação às empresas menores, ainda sobre o estudo o autor testou duas hipóteses sobre o tamanho do empreendimento e a prática de gestão financeira, concluindo que quanto maior o tamanho e o desejo de crescimento do empreendimento maior é a prática de gestão por parte dos gestor.

Por sua vez, o estudo desenvolvido por Silva (2015) que teve como objetivo investigar a importância da contabilidade para o pequeno produtor rural do município de Catanduva-PR, aplicado para 750 agricultores propiciando relatórios de análises e servindo como base de dados para a utilização dos instrumentos de gestão por parte dos agricultores, evidenciou que o déficit de conhecimento e o nível de formação baixo pode resultar na falta de gestão financeira dentro das organizações rurais, com isso, acarretando problemas no controle financeiro.

De acordo com Lisboa (2015), que investiga o uso das ferramentas de gestão por proprietários rurais de UberlândiaMG, menos da metade dos agricultores entrevistados realizam controle financeiro na propriedade, destacando que o envelhecimento do produtor rural e o baixo nível de escolaridade.

Já para De Souza (2016), que analisou o método utilizado na gestão financeira produtores rurais dos municípios de Colorado do Oeste e Cabixi-Rondônia, os empreendimentos rurais com toda importância que tem na sua produção alimentar, apresenta vários problemas, relacionados ao controle financeiro, por se tratar de uma organização que estão estruturadas de forma familiar e são administrada pelo próprio produtor, que apresenta pouco conhecimento para gerenciar os processos financeiros da sua atividade rural. Para o autor, isso pode se justificar, pelo fato da maioria das atividades agrícolas no Brasil não levarem em consideração todo o processo produtivo financeiro, e que o administrador pouco ou não conhece o processo da gestão e controle financeiro, contudo o agricultor não separa gastos domiciliares dos gastos da propriedade.

De Freitas Santos (2019) propõe no seu trabalho uma análise da relação dos fatores culturais e escolaridade com a aplicação do fluxo de caixa por parte dos agricultores de Mato Grosso, observou-se a existência de alguns aspectos que podem fazer com que os produtores rurais não venham a realizar o fluxo de caixa dentro das sua propriedades, portanto terem um menor controle gerencial financeiro, destacando que o baixo nível escolaridade do produtor rural pode ser um dos fatores de interferência direta sobre a não utilização do fluxo de caixa, pois além da resistência de utilizar a método o fator dificulta a interpretação das informações gerados pela ferramenta, certamente a utilização pode ficar comprometida.

Nessa conjuntura, é notório que ainda em tempos recentes a tomada de decisão do pequeno produtor rural é tomada por cultura e tradição sem fazer uso de práticas de planejamento da gestão (Troian, 2009). A pesquisa realizada por Ulrich (2009), destaca a importância de uma adequação dos meios de gerenciamento nas empresas rurais, sendo uma realidade fundamental para alcançar resultados de produtividade que garantam a sustentabilidade e o sucesso do empreendimento. Para tanto, o autor evidencia que as práticas de planejamento e controle da gestão da produção tem sua importância na avaliação do desempenho e dos resultados obtidos ao longo do desenvolvimento da atividade.

De acordo com a estudo realizado por Silva, Rech e Rech (2010) na cidade de Guaramirim/SC, que buscou analisar a prática de planejamento e gestão nas propriedades rurais da localidade, tem-se evidências sobre a necessidade do produtor rural 
fazer uso das práticas de planejamento da gestão da produção, para viabilizar e introduzir estratégias produtivas, comercial, recursos humanos e uma gestão financeira que lhe permita esta dentro do orçamento financeiro planejado. Se formando, assim, uma corrente de estudos que investiga o processo de tomada de decisão dos agricultores familiares no que compreende etapas de planejamento nos seus diferentes tipos estratégico, tático e operacional, e suas consequências como forma de obter vantagem competitiva do negócio (Da Silva, Da Silva Pereira \& Sproesser, 2011).

Nesse âmbito, para Brun (2013), o desafio está no produtor se motivar a conhecer seu ambiente, sua realidade, no que consiste em aspectos de mercado, recursos humanos, políticas governamentais, alternativas financeiras, e outros. Sendo, como destaca Taliatine, De Jesus Ramos e Favoretto (2015), de extrema necessidade de que o produtor rural tenha todo conhecimento a respeito do seu papel no cenário econômico interno e externo buscando, desse modo, constante melhorias das suas técnicas de produção e, desse modo, despertem interesse por melhorias na sua gestão financeira.

Outra tendência no meio rural é a inserção de tecnologia para otimizar a produção rural, principalmente diante da expansão do crédito rural no país para investimento de melhorias do negócio. O trabalho de Batalha, Buainain e Sousa Filho (2005), possibilita identificar que o uso dos meios tecnológicos dentro das organizações rurais assume um papel importante para toda e qualquer empresa que visa sua longa continuidade. Nesse estudo, os autores discutem alguns desafios gerenciais na agricultura familiar, e um dos pontos pesquisados é a utilização dos meios tecnológicos pelo produtor rural, quando a maioria ainda não faz uso significativo das ferramentas adequadas de gerenciamento. Ainda assim, vale destacar o desempenho superior apresentado pelos agricultores que além de pesquisar investem em tecnologias na sua atividade, comparado aos que não decorrem dessa prática.

De acordo com Della Colleta (2013), que investigou os produtores de grãos de São Gabriel do Oeste-MG, os produtores rurais que investem em tecnologia para sua produção são mais cautelosos quanto à gestão da atividade de modo, demonstrando preocupação com a produção e expansão do seu empreendimento. Desse modo, o autor destaca que esses tendem a apresentar uma maior tendência quanto a um gerenciamento do controle financeiro melhor em comparação aos que não fazem uso desses instrumentos. Ao considerar toda a discussão exposta nessa seção esse estudo testa seis hipóteses, apresentadas no Quadro 1.

Quadro 1 - Hipóteses do estudo.

\begin{tabular}{|c|c|}
\hline Hipóteses & Base teórica \\
\hline \multicolumn{2}{|l|}{ Perfil socioeconômico } \\
\hline $\begin{array}{l}\text { H1. Quanto menor a idade do produtor rural há uma maior tendência à adoção de } \\
\text { práticas de gestão financeira mediante acesso à informação. }\end{array}$ & \multirow{2}{*}{$\begin{array}{l}\text { Santos (2009); } \\
\text { Lisboa (2015) }\end{array}$} \\
\hline $\begin{array}{l}\text { H2. Quanto maior a escolaridade de produtor rural a uma tendência de um maior uso } \\
\text { da prática de gestão financeira. }\end{array}$ & \\
\hline \multicolumn{2}{|l|}{ Características do empreendimento rural } \\
\hline H3. Quanto maior o empreendimento mais frequente as rotinas de gestão financeira. & \multirow{2}{*}{$\begin{array}{l}\text { Silva, Rech e Rech } \\
\text { (2010); De Souza } \\
\text { (2016) }\end{array}$} \\
\hline $\begin{array}{l}\text { H4. Quanto mais o empreendimento rural é estruturado na forma familiar maior } \\
\text { tendência à falta de práticas de gestão financeira. }\end{array}$ & \\
\hline \multicolumn{2}{|l|}{ Atitudes de planejamento } \\
\hline $\begin{array}{l}\text { H5. Quanto mais o produtor utiliza práticas de planejamento da gestão de produção } \\
\text { maior são as chances desse produtor fazer uso de práticas de gestão financeira. }\end{array}$ & $\begin{array}{l}\text { Ulrich (2009); Silva, } \\
\text { Rech e Rech (2010); } \\
\quad \text { Moreira (2017) }\end{array}$ \\
\hline \multicolumn{2}{|l|}{ Uso de tecnologia } \\
\hline $\begin{array}{l}\text { H6. Quanto mais o produtor pesquisa e investe em tecnologia na sua propriedade } \\
\text { para aumento de produção maior é a tendência desse produtor fazer uso de práticas } \\
\text { de gestão financeira. }\end{array}$ & $\begin{array}{l}\text { Batalha, Buainain e } \\
\text { Sousa Filho (2005); } \\
\text { Della Colleta (2013) }\end{array}$ \\
\hline
\end{tabular}

Fonte: Autores. 


\section{Metodologia}

A presente pesquisa se caracteriza como aplicada, exploratória com abordagem quantitativa. Os procedimentos técnicos empregados baseiam-se no método survey por meio de questionário, tomando como base a pesquisa de Silva, Rech e Rech (2010), Carvalho e Schiozer (2012) e Silva e Malaquias (2020).

O instrumento utilizado para a coleta dos dados foi o questionário com perguntas de múltipla escolha, tendo sido aplicados 90 questionários, com aplicação realizada de dezembro de 2020 a março de 2021, dividido em três partes: I) voltada ao perfil e características socioeconômicas do produtor rural; II) relativas às características de controle da gestão financeira tomadas nas propriedades rurais; III) relacionado à utilização de planejamento nas propriedades rurais como resumido no Quadro 2.

Quadro 2 - Resumo das questões abordadas na pesquisa.

\begin{tabular}{|c|c|c|}
\hline ASPECTO & VARIÁVEIS & REFERÊNCIAS \\
\hline $\begin{array}{c}\text { Característica } \\
\text { de controle e } \\
\text { gestão } \\
\text { financeira }\end{array}$ & $\begin{array}{l}\text { Costumo fazer controle (anotações) do que GASTO (custos e despesas) na } \\
\text { produção em caderno de anotações e/ou planilhas - gf1 } \\
\text { Costumo fazer controle (anotações) do que GANHO (receitas) com a } \\
\text { produção em caderno de anotações e/ou planilhas - gf2 } \\
\text { Costumo fazer controle de contas bancárias - gf3 } \\
\text { Costumo fazer controle das contas a receber - gf4 } \\
\text { Costumo fazer controle de contas a pagar - gf5 } \\
\text { Costumo fazer controle de estoque - gf6 } \\
\text { Costumo fazer controle dos fornecedores - gf7 } \\
\text { Costumo fazer controle dos investimentos realizados na propriedade - gf8 } \\
\text { Consigo separar gastos da minha casa(familiar) dos gastos da minha } \\
\text { produção rural - gf9 } \\
\text { Costumo fazer orçamento para compras e gastos (despesas e custos) de } \\
\text { produção - gf10 } \\
\text { Costumo fazer orçamento de comercialização - gf11 } \\
\text { Tenho o hábito de comparar despesas de uma safra para a outra - gf12 } \\
\text { Sei efetivamente, se minhas atividades estão dando lucro ou prejuízo-gf13 } \\
\text { Compro somente o mínimo necessário - gf14 } \\
\text { Ao realizar algum investimento costumo fazer análise de viabilidade - gf15 } \\
\text { Faço uso de fluxo de caixa - gf16 } \\
\text { Faço uso de balanço patrimonial - gf17 } \\
\text { faço uso de demonstração de resultados de exercício (DRE) - gf18 }\end{array}$ & $\begin{array}{c}\text { Silva, Rech e } \\
\text { Rech (2010); } \\
\text { Carvalho e } \\
\text { Schiozer (2012); } \\
\text { Lisboa (2015); } \\
\text { De Souza (2016); } \\
\text { Moreira (2017) }\end{array}$ \\
\hline $\begin{array}{l}\text { Características } \\
\text { de } \\
\text { planejamento }\end{array}$ & $\begin{array}{l}\text { Planejamento estratégico } \\
\text { Faço diversificação da produção proteger de frustrações de safras, de } \\
\text { preços baixos e diminuir as variações da minha renda-pe1 } \\
\text { Costumo atribuir atividades aos filhos com o objetivo de fazer meu sucesso } \\
\text { e dar continuidade a propriedade rural no futuro-pe2 } \\
\text { Procuro informações sobre o preço histórico dos produtos (séries históricas } \\
\text { de preços) - pe3 } \\
\text { Antes do escalonamento da produção, já sei quem será o comprador dos } \\
\text { meus produtos - pe4 } \\
\text { Costumo avaliar os possíveis riscos de acontecer algo inesperado com a } \\
\text { produção - pe5 } \\
\text { Realizo o controle de ervas daninhas - pe6 } \\
\text { Faço a utilização de agrotóxicos registrados no Ministério da Agricultura } \\
\text { para as culturas exploradas - pe7 } \\
\text { Obedeço às recomendações a quantidade e frequência da aplicação dos } \\
\text { agrotóxicos - pe8 } \\
\text { Faço a utilização de métodos alternativos aos químicos no controle de } \\
\text { pragas/doenças - pe9 }\end{array}$ & $\begin{array}{c}\text { De Souza (2016); } \\
\text { Moreira (2017); } \\
\text { Stacke (2017) }\end{array}$ \\
\hline
\end{tabular}




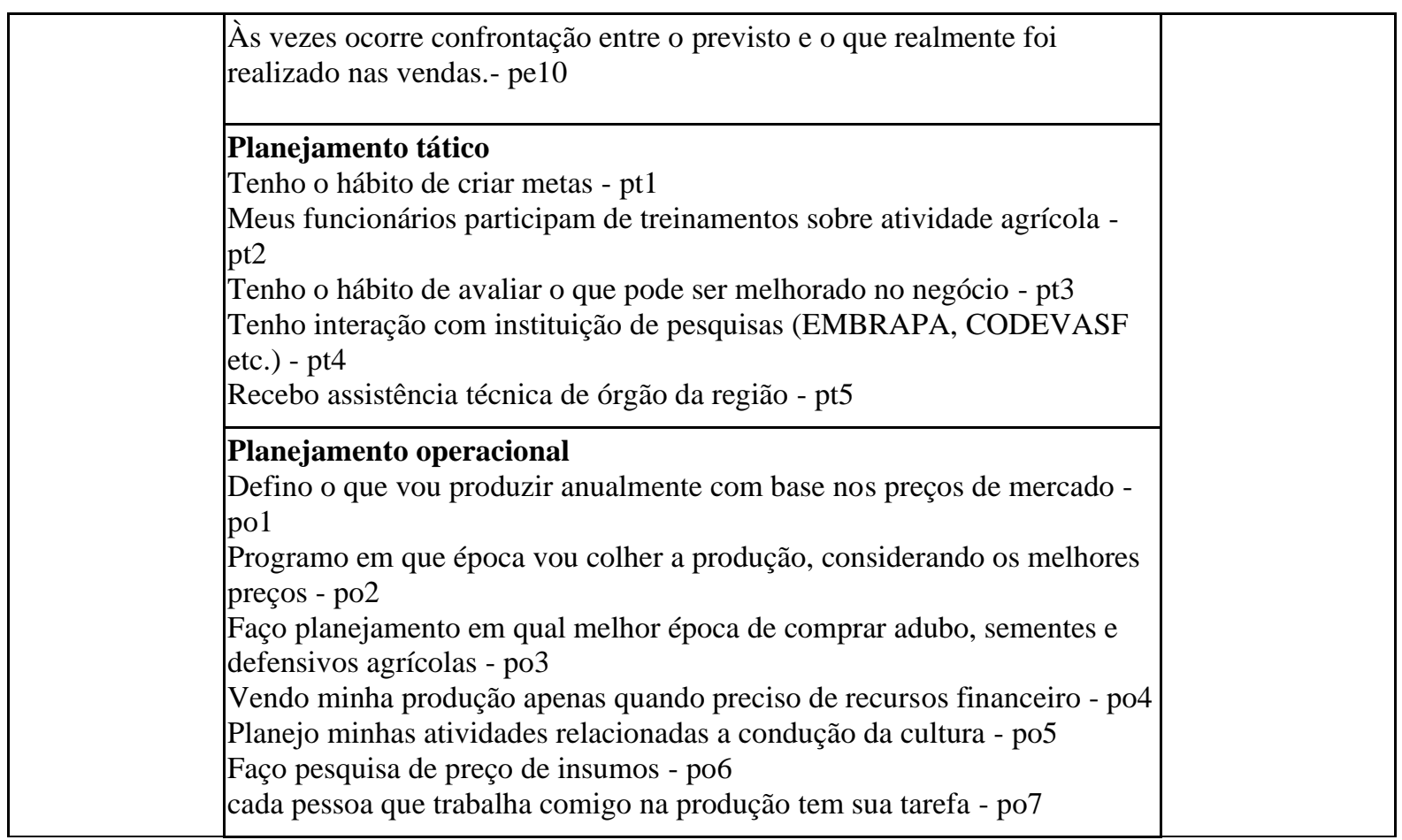

\section{$\mathrm{P}$}

Fonte: Autores.

ortanto, foi adotado o modelo questionário survey neste trabalho, que obtém os dados e informações necessárias, através da aplicação do questionário aos produtores rurais da microrregião de Salgueiro, por conveniência a coleta de dados foi realizada por meio da plataforma online formulário google, o link de acesso foi divulgado em plataformas de redes sociais WhatsApp e por E-mail das associações e sindicatos rurais da região investigada.

\subsection{Construção das variáveis}

A análise é composta por uma variável dependente sobre práticas de gestão financeira e variáveis independentes correspondentes a características socioeconômicas sobre idade, renda, escolaridade, tamanho da área de produção, gerenciamento da propriedade, aspectos de comercialização, uso de tecnologia, e adoção de planejamento de gestão.

A variável dependente práticas de gestão financeira, com base em Carvalho e Schiozer (2012), é calculada a partir de uma pontuação de frequência (isto é, um score) sobre práticas de gestão financeira dada pela soma das respostas dadas nas questões do questionário apresentado no Quadro 2 que seguem uma escala do tipo 5 pontos variando de nunca (1) à sempre (5).

As variáveis explicativas sobre perfil socioeconômico gênero, idade, renda e tipo de atividade foram do tipo dicotômicas, utilizando dummys para representá-los. Desse modo, o perfil analisado foi produtores do gênero masculino, menores de 21 anos, com renda de até 2 mil reais e que desenvolvem atividade do tipo de agricultura familiar - 1 , e 0 - caso contrário. Já a variável escolaridade foi do tipo categórica, variando de 0 - analfabeto à 5 - Especialização.

Sobre a propriedade, para o tamanho desta utilizou-se a área em hectares. Para a variável participação no mercado, considerou a soma da atuação dos produtores na comercialização em feiras, fornecimento direto para supermercados, CEASA, bares e/ou restaurantes e intermediários, sobre o pressuposto de que quanto maior a participação maior a preocupação com cuidados de gestão financeira como variável de controle na análise. Como houve respondentes informando que também fazem uso para consumo próprio, para a variável mercado ponderou essa informação no indicador construído por 0.

Sobre as variáveis de planejamento, as questões foram formuladas considerando aspectos de planejamento 
operacional, tático e estratégico. A variável de planejamento operacional foi construída pela soma da frequência de comportamentos voltados para o processo da atividade de curto prazo, baseando-se em Munaretto, Dellarmelin e Rosin (2019), sobre uso da terra, tempo de plantação e colheita, compra de insumo, planejamento de volume de produção e outros (po1 - po7 no Quadro 2). Para construção da variável de planejamento tático utilizou-se a soma das atitudes de objetivos de médio prazo, tais como, práticas de planejamento de metas, uso de treinamentos, avaliação de melhorias do negócio e contato com instituições de fomento da região para assistência e orientações técnicas (pt1- pt5 no Quadro 2). Por fim, a variável planejamento estratégico foi construída pelo somatório de questões voltadas para objetivos de longo prazo, tais como, diversificação da produção, controle de pragas, planejamento do escoamento da produção e uso de insumos pensando em sustentabilidade.

Por fim, para a variável tecnologia, foi construído um indicador que soma uso de tecnologias na produção como número de tratores, número de arados de tração animal, número de arados de tração mecânica, número de máquinas para plantio, número de máquinas para colheita.

\subsection{Estratégia empírica}

Para se testar as hipóteses propostas no estudo (H1-H6) é necessário analisar empiricamente qual a relação da frequência de práticas relacionadas à gestão financeira com atributos de perfil socioeconômico, de caracterização do empreendimento rural e de atitudes de planejamento de gestão. Desse modo, se tratando da variável resposta um score construído a partir de respostas dadas a questões da escala do tipo 5 pontos variando de nunca (1) à sempre (5) para se testar as hipóteses propostas, num primeiro momento se analisará os resultados mediante Análise de Regressão Múltipla, por meio do método dos Mínimos Quadrados Ordinários (MQO)1.

Ademais, com base no estudo de Carvalho e Schiozer (2012), para uma maior robustez da análise será utilizada regressão logística múltipla considerando a mediana e a distribuição por quartil do indicador construído para práticas de gestão financeira, e como pontos de corte para uma construção de variáveis dicotômicas melhor discutidas na exposição dos resultados, cuja especificação do modelo se dará da seguinte forma:

$$
\text { Rotinas de } G F_{i}=\sum_{i=1}^{n} \beta_{1} X_{i}+\beta_{2} \text { esc }_{i}+\beta_{3}(\text { merc } * \text { area })_{i}+\beta_{4} \text { famil }_{i}+\sum_{i=1}^{n} \beta_{5} \text { plan }_{i}+\beta_{6} \text { tec }_{i}+v_{i}
$$

Onde Rotinas de GF$i$ é o indicador de práticas de gestão financeira do produtor rural i, $X_{i}$ é um vetor de características dos produtores como gênero, idade, renda do produtor i, $e s c_{i}$ é a variável categórica de escolaridade do produtor rural i, (merc*area $)_{i}$ é área do produtor rural ponderada pela dimensão de mercado que com o qual o produtor i comercializa,

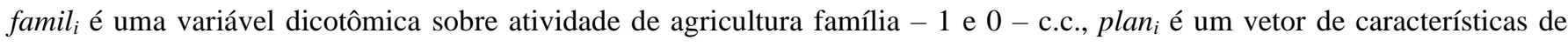
planejamento de gestão agrupados nos tipos estratégico, operacional e tático, tec $_{i}$ indicador de uso de tecnologia na produção e $v_{i}$ é vetor de termo erros aleatórios e que assume as propriedades estatísticas usuais.

\section{Resultados e Discussão}

Com objetivo de testar as hipóteses construídas neste estudo, sobre determinantes da prática de gestão financeira por produtores rurais, tomando como base o estudo de Carvalho e Schiozer (2012), analisa-se os resultados de três modelos

\footnotetext{
${ }^{1}$ Ver Gujarati (2011).
} 
apresentados na Tabela 2. Para a especificação (1) investiga-se o que determina o uso de práticas de gestão financeira no empreendimento rural a partir de estimadores de mínimos quadrados ordinários (OLS).

$\mathrm{Na}$ especificação (2) recorre-se ao modelo logístico, para estimar as rotinas de gestão financeira a partir de uma variável dicotômica comparando os produtores rurais em dois grupos: 1 - os que adotam aspectos da gestão financeira com maior frequência (score acima da mediana); 0 - e os que adotam a referida prática numa menor frequência (score abaixo da mediana). Por sua vez, nos modelos (3) e (4), com o objetivo de dar maior precisão à análise, isto é, maior robustez, em substituição à mediana utiliza-se respectivamente, $\mathrm{o} 1^{\circ} \mathrm{e}$ o $3^{\circ}$ quartis de distribuição de score como ponto de corte.

Os resultados da Tabela 1 sugerem que, contrariamente ao previsto nas hipóteses H1, H3 e H6, não se tem evidência para confirmar que idade, tamanho do empreendimento (mercado) e uso de tecnologia na produção influenciam a frequência das práticas de gestão financeira nos empreendimentos de agricultura familiar na microrregião de Salgueiro.

Com relação à hipótese $\mathrm{H} 4$, quanto mais o empreendimento rural é estruturado na forma familiar maior tendência à falta de práticas de gestão financeira, embora as especificações (1) e (2) tenha indicado relação negativa e significativa a 5\%, -corroborando evidências de Souza (2016) que no empreendimento rural do tipo familiar há uma maior tendência da falta de uso da elementos da gestão financeira quando esses agricultores tomam decisão mais por tradição, levando em consideração a cultura dos mais velhos sobre como administrar -- não houve significância estatística a níveis usuais nas especificações (3) e (4). Desse modo, mesmo existindo indícios sobre a existência da relação investigada, a evidência não é forte o suficiente para confirmar a hipótese H4. Com resultado similar, é possível verificar em relação à hipótese H5 sobre planejamento de gestão que o planejamento tático estava comprometendo a variabilidade dos modelos, não tendo sido analisado nos modelos finais.

Tabela 1 - Regressões logísticas para análise dos determinantes da frequência de uso de instrumentos da gestão financeira na tomada de decisão.

\begin{tabular}{|c|c|c|c|c|}
\hline \multirow{3}{*}{ Variáveis } & \multicolumn{4}{|c|}{ Frequência da prática de gestão financeira } \\
\hline & $\begin{array}{l}(1) \\
\text { OLS }\end{array}$ & $\begin{array}{l}(2) \\
\text { Logistic }\end{array}$ & $\begin{array}{c}(3) \\
\text { Logistic }\end{array}$ & $\begin{array}{l}(4) \\
\text { Logistic }\end{array}$ \\
\hline & $\begin{array}{c}\text { Coeficientes } \\
\beta\end{array}$ & $\begin{array}{c}\text { Coeficientes } \\
\beta\end{array}$ & $\underset{\beta}{\text { Coeficientes }}$ & $\begin{array}{c}\text { Coeficientes } \\
\beta\end{array}$ \\
\hline Idade: Menor que 21 anos (H1) & $\begin{array}{c}1,2770 \\
(13,5100)\end{array}$ & $\begin{array}{c}13,5800 \\
(1,455)\end{array}$ & $\begin{array}{l}14,3100 \\
(2,400)\end{array}$ & $\begin{array}{l}-15,1500 \\
(2,400)\end{array}$ \\
\hline Gênero: Masculino (controle) & $\begin{array}{c}3,3370 \\
(3,4560)\end{array}$ & $\begin{array}{c}0,0763 \\
(0,8121)\end{array}$ & $\begin{array}{c}0,4044 \\
(0,8474)\end{array}$ & $\begin{array}{l}-0,3650 \\
(1,0470)\end{array}$ \\
\hline Escolaridade (H2) & $\begin{array}{c}3,4310 * * * \\
(1,1150)\end{array}$ & $\begin{array}{r}0,6165^{* *} \\
(0,2680)\end{array}$ & $\begin{array}{c}1,0930^{* * *} \\
(0,3288)\end{array}$ & $\begin{array}{c}0,8870 * * \\
(0,4108)\end{array}$ \\
\hline $\begin{array}{l}\text { Principal atividade: Agricultura familiar } \\
\text { (H4) }\end{array}$ & $\begin{array}{c}-8,1150 * * \\
(3,4170)\end{array}$ & $\begin{array}{c}-2,3230 * * \\
(0,9273)\end{array}$ & $\begin{array}{l}-0,3766 \\
(0,8962)\end{array}$ & $\begin{array}{l}-0,7108 \\
(0,9749)\end{array}$ \\
\hline Renda: até 2 mil reais (controle) & $\begin{array}{c}1,4280 \\
(3,2240)\end{array}$ & $\begin{array}{c}0,3126 \\
(0,7649)\end{array}$ & $\begin{array}{l}-0,0775 \\
(0,8794)\end{array}$ & $\begin{array}{l}-0,6386 \\
(0,9428)\end{array}$ \\
\hline Total de tecnologia (H6) & $\begin{array}{c}0,0436 \\
(-0,9583)\end{array}$ & $\begin{array}{l}-0,0374 \\
(0,2341)\end{array}$ & $\begin{array}{l}-0,2169 \\
(0,2659)\end{array}$ & $\begin{array}{c}0,0099 \\
(0,2803)\end{array}$ \\
\hline
\end{tabular}




\begin{tabular}{|c|c|c|c|c|}
\hline Mercado X Área (H3) & $\begin{array}{l}-0,0098 \\
(0,0254)\end{array}$ & $\begin{array}{l}-0,0058 \\
(0,0062)\end{array}$ & $\begin{array}{l}-0,0015 \\
(0,0088)\end{array}$ & $\begin{array}{l}-0,0016 \\
(0,0053)\end{array}$ \\
\hline Crédito Rural (controle) & $\begin{array}{c}3,6940 \\
(3,0820)\end{array}$ & $\begin{array}{c}0,6766 \\
(0,7540)\end{array}$ & $\begin{array}{l}1,6090^{* * *} \\
(0,8174)\end{array}$ & $\begin{array}{c}0,2319 \\
(1,0660)\end{array}$ \\
\hline Planejamento Estratégico (H5.1) & $\begin{array}{c}0,7736 * * * \\
(0,1958)\end{array}$ & $\begin{array}{c}0,0689 \\
(0,0473)\end{array}$ & $\begin{array}{c}0,1025 \\
(0,0515)\end{array}$ & $\begin{array}{c}0,1313 * * \\
(0,0609)\end{array}$ \\
\hline Planejamento Operacional (H5.2) & $\begin{array}{c}1,0270 * * * \\
(0,2564)\end{array}$ & $\begin{array}{c}0,2499 * * * \\
(0,0764\end{array}$ & $\begin{array}{c}0,0722 \\
(0,0653)\end{array}$ & $\begin{array}{c}0,3224 * * * \\
(0,1019)\end{array}$ \\
\hline Constante & $\begin{array}{c}1,1960 \\
(7,1340)\end{array}$ & $\begin{array}{c}-7,9730 * * * \\
(2,2010)\end{array}$ & $\begin{array}{c}-5,6750 * * * \\
(2,0570)\end{array}$ & $\begin{array}{c}-14,7900 * * * \\
(4,2110)\end{array}$ \\
\hline Observações & 90 & 90 & 90 & 90 \\
\hline Pseudo- $R^{2}$ & $64,33 \%$ & $50,97 \%$ & $47,41 \%$ & $59,57 \%$ \\
\hline$\%$ de acerto & - & $87,86 \%$ & $78,39 \%$ & $67,54 \%$ \\
\hline
\end{tabular}

Nota: Erros-padrão entre parênteses. ***Estatisticamente significante a $1 \% * *$ Estatisticamente significante a $5 \%$. *Estatisticamente significante a 10\%. Fonte: Autores. a partir dos resultados evidenciados.

Em se tratando da referida hipótese no que compete à frequência de atitudes quanto a planejamento estratégico, quanto a diversificação da produção, controle de pragas, planejamento do escoamento da produção e uso de insumos pensando em sustentabilidade percebe-se embora indícios de relação nas especificações (1) e (4), aos níveis de significância de 1\% e 5\%, respectivamente, uma relação não evidenciada nas especificações (2) e (3) como uma relação não forte o suficiente para que a H5 seja confirmada.

Em relação ao planejamento operacional, embora apresentando relação positiva e significante ao nível de $1 \%$ nas especificações (1), (2) e (4), sugerindo, conforme Munaretto, Dellarmelin e Rosin (2019), planejamento quanto ao uso da terra, tempo de plantação e colheita, compra de insumo, planejamento de volume de produção e outros, não é evidenciado resultado na especificação (3), comprometendo também a confirmação da hipótese H5.

Todas as quatro especificações mostradas na Tabela 1 dão forte suporte para a confirmação da hipótese H2, isto é, quanto maior o nível de escolaridade maior as chances do uso de práticas de gestão financeira aos níveis de $1 \%$ ou $5 \%$ de significância estatística a depender da especificação. Esse resultado corrobora os achados de Silva (2015) e Lisboa (2015), demonstrando o quanto a escolaridade contribui à sustentabilidade dos negócios a partir do uso de práticas de gestão da área financeira permitindo que o produtor utilize-se de instrumentos para por exemplo, reduzir custos operacionais, otimizar o controle financeiro, permitir maior eficiência quanto controle de estoque, mais informações para se identificar falhas, tomar decisões e realizar correções.

Um outro resultado que aparece na especificação (3), mas apenas nessa especificação e, desse modo, não apresenta força significativa para ser um efeito confirmado sobre as práticas de gestão financeira é a variável crédito rural, com indícios que a frequência de uso de fontes externas de financiamento está positivamente correlacionada aumentando as chances de maior frequência quanto a atitudes de controle de gestão financeira pelos produtores rurais, corroborando, em partes relação levantada por Carvalho e Schiozer (2012) para micro e pequenas empresas de Minas Gerais e São Paulo.

\section{Conclusão}


Com os avanços da globalização, a agricultura não pode mais ser observado só no âmbito da produção, e sim ter a propriedade como uma organização, que requer conhecimento do gestor e utilização das ferramentas gerenciais. a competitividade de mercado exige que o agricultor inove em suas estratégias de produção e da gestão da propriedade rural.

A questão central que esse estudo buscou identificar refere-se aos fatores determinantes da utilização da gestão financeira pelo agricultor rural da microrregião de Salgueiro em seus estabelecimentos e nas tomadas de decisões. Nesse contexto, em busca de testar as hipóteses propostas, foram utilizados os estimadores de OLS e de regressão logística para identificar e analisar as hipóteses apresentadas na pesquisa. Os resultados sugerem significativa relação entre a escolaridade e as práticas de gestão financeira pelos produtores rurais, assim como, relação positiva entre uso de planejamentos de gestão dos tipos estratégico e operacional e as atitudes práticas de gestão financeira no dia a dia para uma mais eficiente tomada de decisão na microrregião de Salgueiro. Sugerindo políticas públicas na região que incentive o aumento da escolaridade dessa população.

Baseado nos resultados, evidencia-se a necessidade do poder público em conjunto com órgãos locais e regionais como, Secretaria de agricultura, Adagro, Ipa, Sindicato Rural apresentarem projetos, incentivos e acompanhamento técnico especializado, além de fornecerem palestras e treinamentos para os funcionários e para os produtores rurais, ainda cabe destacar a possibilidade do envolvimento das instituições educativas como o Instituto Federal Campus Sertão central, que possui o curso de técnico em agropecuária, que como forma de agregar conhecimento e incentivo aos alunos da instituição seria buscar um aumento nas bolsas remuneradas para projetos ,contando com a participação dos alunos e servidores com o intuito de qualificar e fornecer orientação na condução da atividade rural.

Ainda cabe mencionar e sugerir em relação aos fatores de planejamento e gestão financeira, envolvimento de instituições educativas como Upe com a participação dos graduandos de administração juntamente com os professores, assim como, a Universidade Federal Vale do São Francisco (Univasf Campus Salgueiro) com o integrantes do curso de Engenharia da Produção, ambos os cursos localizados na cidade de Salgueiro, com palestras e acompanhamentos de controle de gestão, por meio de projetos, outra possibilidade reside em propor modelos simplificados de organização e controle financeiro para auxiliar os produtores desse segmento, com vistas a contribuir com a melhoria do desempenho desse importante setor da economia.. Além das propostas citadas cabe às autoridades públicas locais buscar meios para solucionar os problemas encontrados.

Dentre as limitações desse estudo pode-se destacar o aceite dos produtores rurais em responderem ao questionário, bem como dificuldades por alguns de compreensão das questões. No entanto, embora tenha sido realizada por meios digirais foi possível ter na amostra produtores analfabetos respondendo, já que além do acesso ao próprio google forms para responder a aplicação se deu também por contato telefônico, e o que pode ter ocorrido é não ter levado em consideração produtores que não dispõe de telefone.

Por fim, como sugestão de trabalhos futuros sugere-se análise de causalidade entre práticas de gestão financeira e desempenho do negócio do produtor rural, como exemplo uso de análise fatorial e aplicação de equações estruturais com objetivo de compreender melhor as relações sobre práticas de gestão financeira e sustentabilidade do negócio.

\section{Agradecimentos}

Este estudo foi parcialmente financiado pela Fundação de Amparo a Ciência e Tecnologia de Pernambuco.

\section{Referências}


Borilli, S. P., Philippsen, R. B., Ribeiro, R. G., \& Hofer, E. (2005). O uso da contabilidade rural como uma ferramenta gerencial: um estudo de caso dos produtores rurais no município de Toledo-PR. Revista de Ciências Empresariais da UNIPAR, 6(1), 77-95.

Bressan, V. G. F., Braga, M. J., \& Bressan, A. A. (2003). Avaliação financeira das cooperativas de crédito rural do estado de Minas Gerais. Organizações Rurais \& Agroindustriais, 5(2), 1-15.

Brun, R. (2013). Planejamento estratégico aplicado a uma propriedade rural de atividade leiteira. Monografia Final de Curso, Faculdade de Horizontina, Horizontina.

Callado, A. A. C., \& Callado, A. L. C. (1999). Custos: um desafio para a gestão no agronegócio. In Anais do Congresso Brasileiro de Custos-ABC.

Carvalho, C. J. D., \& Schiozer, R. F. (2012). Gestão de capital de giro: um estudo comparativo entre práticas de empresas brasileiras e britânicas. Revista de Administração Contemporânea, 16, 518-543.

Corrêa, R. D. F., Kliemann Neto, F. J., \& Denicol, J. (2016). Revisão de proposições para a gestão econômico-financeira de sistemas produtivos agropecuários: a inter-relação entre fluxo de caixa, sistemas de custos e recursos compartilhados. Custos e @ gronegócio on line, 90840, 440, 113-141.

Colombo, S. (2021). O impacto da pandemia do COVID-19 no transporte coletivo no município de Cuiabá-Mato Grosso. Brazilian Journal of Development, 7(3), 29244-29246.

Dal Magro, C. B., Di Domenico, D., Klann, R. C., \& Zanin, A. (2011). Contabilidade rural: comparativo na rentabilidade das atividades. In Anais do Congresso Brasileiro de Custos-ABC.

de Freitas Santos, E. S., Carvalho, R. G., \& Freire, E. J. (2019). A influência da cultura e escolaridade na aplicabilidade do fluxo de caixa rural. Revista Científica da Ajes, 8(17), 113-122.

de Souza, J. A., da Silva, J. M., Porto, W. S., \& de Souza, E. M. (2016, June). Gestão financeira: um estudo sobre a utilização de controles financeiros na agricultura familiar. In Encontro de Ensino e Pesquisa em Administração da Amazônia.

Della Colleta, B. K., Cezar, I. M., de Souza, C. C., \& Costa, F. P. (2013). Instrumentos de gestão financeira utilizados pelos produtores de grãos de São Gabriel do Oeste, Mato Grosso do Sul. Embrapa Gado de Corte-Artigo em periódico indexado (ALICE).

Freitas, H., Oliveira, M., Saccol, A. Z., \& Moscarola, J. (2000). O método de pesquisa survey. Revista de Administração da Universidade de São Paulo, 35(3), $105-112$.

Garcia, F. F., Rezende, W. F., \& Ferracini, M. J. F. O. (2017). Gestão Financeira. Iturama-MG: Faculdade Aldete Maria.

Gujarati, D. N., \& Porter, D. C. (2011). Econometria básica, v.5, Amgh Editora..

Hisrich, R. D., Peters, M. P., \& Shepherd, D. A. (2014). Empreendedorismo, v9. Amgh Editora.

Hoji, M. (2004). Administração financeira: uma abordagem prática: matemática financeira aplicada: estratégias financeiras: análise, planejamento e controle financeiro. Atlas.

Iudícibus, S. D., \& Marion, J. C. (1999). Introdução à teoria da contabilidade, Atlas.

Kurz, C. L. S., \& Zdanowicz, J. E. (2016). Gestão do fluxo de caixa de propriedades rurais do município de Toropi (RS). Reflexão cooperativista. 4, $31-52$.

Kruger, S. D., Mazzioni, S., \& Boettcher, S. F. (2009). A importância da contabilidade para a gestão das propriedades rurais. In Anais do Congresso Brasileiro de Custos-ABC.

Lisboa, F. C., Medeiros, M. H., Peixoto, J. L. M., Gouveia, L. C., \& do Nascimento, W. R. (2015). Diagnóstico do uso de ferramentas de gestão por proprietários rurais de Uberlândia-MG. Revista Verde de Agroecologia e Desenvolvimento Sustentável, 10(2), 132-138.

Marion, J. C. (2004). Contabilidade da pecuária. Atlas.

Marion, J. C., \& Segatti, S. (2006). Sistema de gestão de custos nas pequenas propriedades leiteiras. Custos e@ gronegócios online, 2(2), 2-7.

Marion, J. C., Cardoso, A., \& Diniz Filho, A. (2010). Contabilidade como instrumento para tomada de decisões. Alínea.

Medeiros, A. F. Q., Porto, W. S., Souza, J. D., \& Oliveira, D. D. L. (2012). Controle e apuração de resultado na agricultura familiar sob a ótica da sustentabilidade de produtores rurais. Custos e agronegócio, 8(3), 154-171.

Miranda, L. C., de Meira, J. M., de Araújo Wanderley, C., \& da Silva, A. C. M. (2003). Indicadores de desempenho empresarial divulgados por empresas norte-americanas. Contabilidade Vista \& Revista, 14(2), 85-103.

Moreira, B. C. M., Gonçalves, M. V., Costa, M. F., \& Ferreira, A. C. (2017). Analisando o uso de instrumentos financeiros nas práticas de gestão das empresas do setor de confecção e facção do município de Formiga/MG. Revista da Micro e Pequena Empresa, 11(1), 87-107.

Muller, A. N., \& Antonik, L. R. (2008). Análise financeira: uma visão gerencial: guia prático com sugestões e indicações da análise financeira das organizações. Atlas.

Naves, I., \& da Silva Costa, S. T. (2021). As consequências para o produtor rural diante da falta de exercício da contabilidade rural. Revista GeTeC, 10(25), $52-62$.

Padoveze, C. L. (2010). Contabilidade gerencial. IESDE BRASIL SA. 
Research, Society and Development, v. 10, n. 10, e27101018555, 2021

(CC BY 4.0) | ISSN 2525-3409 | DOI: http://dx.doi.org/10.33448/rsd-v10i10.18555

Silva, M. Z., Rech, L. C., \& Rech, G. M. (2010). Estudo sobre as práticas de gestão utilizadas no gerenciamento das pequenas propriedades rurais de Guaramirim. Revista Ciências Sociais em Perspectiva, 9(17), 57-74.

Santos, P. L. S., \& DE Azevedo, E. O. (2009). Perfil sócio-econômico de produtores de leite do estado da Paraíba, Brasil. Revista Caatinga, $22(4), 260-267$.

Silva, A. F., \& Malaquias, R. F. (2020). Fatores Associados à Adoção de Práticas de Gestão Financeira por Produtores Rurais do Triângulo Mineiro. Revista de Educação e Pesquisa em Contabilidade (REPeC), 14(3), 328-351.

Silva, M. E. D., \& da Silva Andrade, P. H. (2017). Aplicação de ferramentas de gestão de custos na Fazenda São Gonçalo, no município de Banabuiú-CE. Revista Expressão Católica, 5(1), 67-75.

Silva, M. Z., Rech, L. C., \& Rech, G. M. (2010). Estudo sobre as práticas de gestão utilizadas no gerenciamento das pequenas propriedades rurais de Guaramirim. Revista Ciências Sociais em Perspectiva, 9(17), 1-18.

Stacke, J. A. (2017). Análise da utilização das ferramentas contábeis gerenciais em micro e pequenas empresas. Monografia (Graduação em Ciências Contábeis) - Universidade do Vale do Taquari - Univates, Lajeado.

Taliarine, A. B., Ramos, D., \& Favoretto, J. R. (2015). A importância da gestão no agronegócio brasileiro. Revista Perspectiva em Gestão, Educação \& Tecnologia, 4(8), 6-15.

Troian, A., Dalcin, D., Troian, A., \& De Oliveira, S. V. (2009). O processo de tomada de decisão dos agricultores familiares produtores de uva na região serra do Rio Grande do Sul: um estudo de caso para o município de Flores da Cunha. Universidade Federal de Santa Maria. 